\title{
Assessing the performance of fire danger indexes in a Mediterranean
}

\section{area}

\author{
Costantino Sirca ${ }^{(1-2)}$, \\ Michele Salis ${ }^{(2-3)}$, \\ Bachisio Arca ${ }^{(3)}$, \\ Pierpaolo Duce ${ }^{(3)}$, \\ Donatella Spano ${ }^{(1-2)}$
}

The fire danger (FD) defines the conditions less or more favourable for a fire ignition success and its propagation. FD indexes, that integrates environmental variables related to FD in more or less complex equations and systems, are widely used in wildfire prone countries for both scientific and operational purposes. Assessing the performance of FD indexes is challenging and this issue is quite debated within the fire community, which has been trying to apply several methodologies to evaluate FD indexes. The main aim of this work is to give a contribution to this effort. The analysis was conducted using data from a fire-prone Mediterranean area (Sardinia island, Italy), where 8 FD indexes were evaluated and compared using different statistical approaches. We calculated the daily FD values for the period 2000-2007 over the study area. A set of statistical tools (namely Spearman rank correlation, Index Value Distribution and Percentile Analysis, and Logistic Regression) were applied to evaluate the performance of each FD index by comparing FD values with fire occurrence indicators. The statistical tests revealed a large variability in FD indexes performance, depending also on fire activity conditions. Our results showed that two of the tested FD indexes reached a good overall performance. Findings from this study can help both the scientific community and local fire managers, supporting the evaluation of early warning systems and fire prevention strategies in the Mediterranean Basin.

Keywords: Fire Risk, Fire Danger Rating, Mediterranean Basin, Fire Occurrence, Wildfire

(Lovreglio et al. 2010, Oliveira et al. 2012, Meddour-Sahar et al. 2013, Curt et al. 2016), while fire spread is mainly governed by weather and climate (Pausas \& FernándezMuñoz 2012, Cardil et al. 2014, Ruffault et al. 2017, Russo et al. 2017), even if fuels and land uses can represent key driving factors (Ruiz-Mirazo et al. 2012, Curt et al. 2013, Fernandes et al. 2014, Salis et al. 2016). Moreover, other aspects (i.e., the socioeconomic context, topography, firefighting resources, and fuel management) also influence the spatial pattern of fire occurrence and spread (Levin et al. 2016, Oliveira et al. 2017, Salis et al. 2018).

Weather variables, alone or in combination with structural/physical vegetation data and topography, are commonly used as input data of fire danger (FD) indexes or systems to estimate the potential FD of a given area. As a general rule, FD indexes are assumed to express potential fire behavior, as for example fire spread rate or intensity. The output of a FD system can be either numeric or dimensionless (index). Especially for operational purposes, the potential FD is often expressed by FD classes (fire danger rating) corresponding to the fire potential occurrence of specific areas with given weather, fuel, and terrain conditions.

Assessing the performance of FD indexes is challenging. A general assumption for FD indexes reliability is the relationship be- tween the estimated potential FD and fire occurrence in terms of spread and intensity potential, and control difficulty. Since in Mediterranean areas most ignitions are caused by anthropogenic causes, it is difficult to determine if an index is more reliable than others only by considering fire occurrence, as high or extreme FD conditions can be observed in days without fire ignitions. In addition, a number of factors (e.g., firefighting efficiency, fuel type, roads, fuel discontinuity) can significantly influence the local fire behavior in a given season and place. As a consequence, results from a given index performance analysis need to be correctly interpreted and applied. However, the comparison between an FD index output and fire occurrence indicators is often adopted to evaluate the FD index performance. Although several concerns related to this approach (e.g., fire indicators are often arbitrarily selected), it represents a key analysis to calibrate the index, assess the index performance, and understand if and how a specific index works well under the tested conditions.

Over recent decades only a few papers attempted to apply statistical methodologies to assess and compare the performance of two or more FD indexes (Andrews et al. 2003, Giannakopoulos et al. 2012). The majority of works have used historical data of fire occurrence (usually fire 


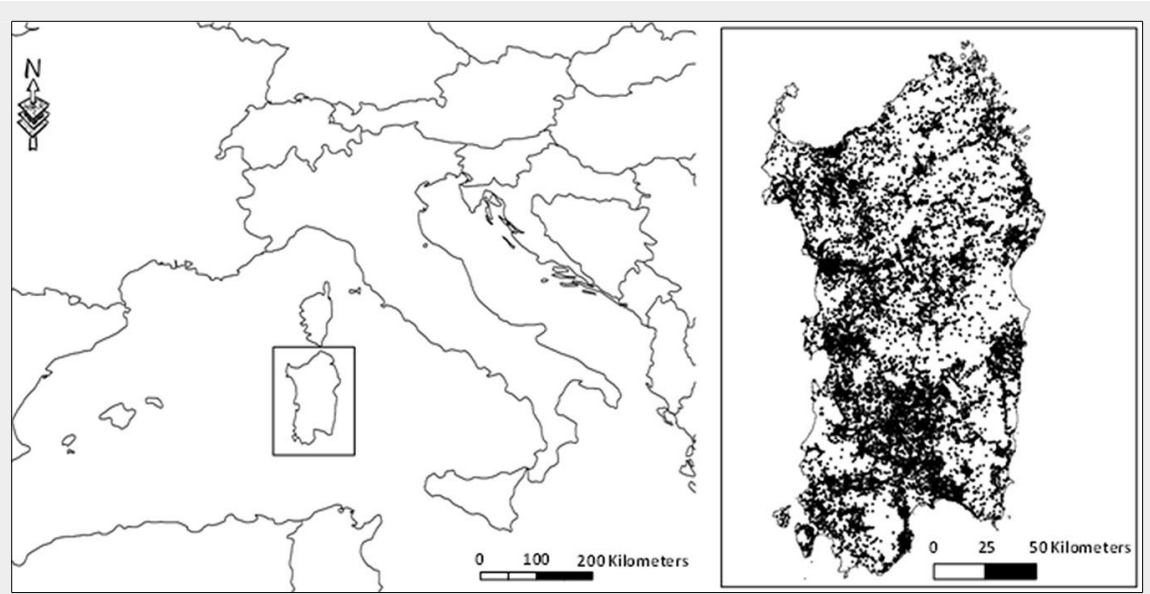

Fig. 1 - Location of the study area (Sardinia, Italy) in the Mediterranean Basin. The fire ignition points of the period 2000-2007 are reported in the figure on the right.

number and burned area) to assess the FD index performance. Viegas (1999) compared 5 FD indexes using fire indicators related to the burned area and number of fires, both with a visual analysis of fire parameters trend and statistical tests. Cruz \& Viegas (1998) gathered fire behavior information from experimental fires to make a comparison with modeled fire behavior using linear regression. The burned area, number of fires per day, firefighting resources, and units employed were used as fire indicators to evaluate FD indexes also by other authors (Krusel et al. 1993).

A few papers, however, have attempted to use advanced statistical techniques to evaluate the performance of FD indexes. Mandallaz \& Ye (1997) applied Poisson models to predict forest fires. Andrews et al. (2003) applied an analysis based on logistic regression and percentile analysis. The logistic regression was used to validate an FD index developed in a Mediterranean Basin area also by Vicente López \& Crespo Abril (2012), and it was also used to predict fire occurrence by Arndt et al. (2013). Percentile analysis was already used to determine FD levels and evaluate the FD indexes performance (Andrews \& Bradshaw 1997, Andrews et al. 2003, Heinsch et al. 2009). However, so far there is not still a general

Tab. 1 - Fire statistics during the period 2000-2007 in Sardinia. (A): The starting and ending dates of the fire season were defined as the dates that follow 10 consecutive days with and without fires, respectively.

\begin{tabular}{cccclccc}
\hline Year & $\begin{array}{c}\text { Number } \\
\text { of fires }\end{array}$ & $\begin{array}{c}\text { Total } \\
\text { burned } \\
\text { area (ha) }\end{array}$ & $\begin{array}{c}\text { Mean } \\
\text { burned area } \\
\text { / fire (ha) }\end{array}$ & & $\begin{array}{c}\text { Days } \\
\text { with }\end{array}$ & $\begin{array}{c}\text { Max fire } \\
\text { number } \\
\text { fires }\end{array}$ & $\begin{array}{c}\text { Max } \\
\text { burned } \\
\text { area / day } \\
\text { (ha) }\end{array}$ \\
\hline 2000 & 2,115 & 15,597 & 7.4 & 13 May - 2 Oct & 172 & 37 & 2,221 \\
2001 & 3,446 & 18,791 & 5.5 & 27 May - 13 Sept & 194 & 55 & 958 \\
2002 & 4,187 & 19,773 & 4.7 & 12 May - 2 Oct & 201 & 67 & 3,024 \\
2003 & 2,998 & 22,445 & 7.5 & 29 May - 13 Oct & 176 & 57 & 2,384 \\
2004 & 3,113 & 21,443 & 6.9 & 5 Jun - 25 Oct & 152 & 76 & 3,250 \\
2005 & 2,995 & 13,313 & 4.4 & 24 May - 5 Nov & 191 & 68 & 1,529 \\
2006 & 2,339 & 7,729 & 3.3 & 12 May - 13 Sept 173 & 45 & 1,493 \\
2007 & 3,325 & 34,358 & 10.3 & 16 May - 29 Oct & 176 & 66 & 12,070 \\
\hline
\end{tabular}

\section{Materials and methods}

\section{Study area and fire data}

Sardinia (Italy - Fig. 1) is the second largest $\left(24,090 \mathrm{~km}^{2}\right)$ island of the Mediterranean Sea. The climate is typically Mediterranean, with a mild and rainy winter (rain occurs mainly in late autumn and spring, mean annual rainfall $500-800 \mathrm{~mm}$ ), and a warm and dry season from June to October. About half of the Sardinian surface area is covered by broad-leaved forests and maquis. Historically, Sardinia is characterized by the highest percentage of fires occurring in Italy, with a long fire season (from late May or June until October). During the study period (2000-2007), Sardinia experienced 24,518 fires and a total surface area of 153,449 ha was burned (source: official fire database of the Regional Administration of Sardinia). July is the month with the highest fire number and the largest burned area. Tab. 1 presents the main statistics of fire events that occurred in Sardinia during the period under investigation.

\section{Fire danger indexes}

A wide variety of FD indexes is described in the literature. Given to the overall purpose of this study, and aiming to evaluate the concordance in the statistical assessment of FD indexes, we selected well known and widely tested FD indexes together with less diffuse ones, including FD indexes developed in very different environmental context. In addition, our choice was based on the input data needed for the calculation of each FD index, that are easily available.

Eight FD indexes were chosen:

1. FWI - Canadian Fire Weather Index of the Canadian Forest Fire Weather Index System (CFFWIS), currently adopted also by the EU Forest Fire Information System EFFIS (Van Wagner 1987, San-MiguelAyanz et al. 2012);

2. KBDI - Keetch-Byram Drought Index (Keetch \& Byram 1968);

3. McArthur Mark 5 (Mk5) Forest and Mark 4 (Mk4) Grassland Fire Danger Index (Noble et al. 1980);

4.FFWI - Fosberg Fire Weather Index (Haines et al. 1983, Sharples et al. 2009);

5. F index (Sharples et al. 2009);

6. Nesterov Index (Nesterov 1949);

7.IPi Propagation index - FAO-UNESCO method (Ventura et al. 2001);

8.IFI - Integrated Fire Index (Sirca et al. 2007).

The FWI is probably the most known and widely used FD index worldwide. It is based on the moisture estimation of three forest fuel classes, and accounts the effect of the wind on fire behaviour. Also the Australian Mk5 and Mk4 are well known and widely used FD indexes, developed for predicting the headfire rate of spread in Australian vegetation characterized by grassland and Eucalyptus forests. The KeetchByram Drought Index and the Nesterov In- 
dex are drought indexes, and are often used as proxies of the fire danger conditions, alone or integrated in more complex fire danger systems. The $\mathrm{F}$ index is a simple index for fire danger rating, which combines temperature and relative humidity (for a coarse estimate of fuel moisture), and wind speed. The IPi and FFWI indexes are used as proxies of fire behaviour characteristics.

IFI is a fire danger rating index developed and calibrated to account for the climate and vegetation characteristics of Mediterranean areas. It is operationally used in Sardinia by the Regional Civil Protection Service for daily fire danger forecasting during the fire season.

$\mathrm{IFI}$ is an empirical fire danger index based on weather and fuel physical inputs. The daily index value is obtained as a sum of four subcomponents (eqn. 1):

$$
I F I=D C+M C+R+F C
$$

where $D C$ is the drought code, $M C$ is the meteorological code, $R$ is the code related to the solar radiation, and $F C$ is the fuel code.

$D C$ represents a parametrization of the water balance (eqn. 2):

$$
D C=\frac{e^{\left(0.261 \frac{R g T}{\lambda}\right)}}{1+\sqrt{P_{a}+\sqrt[3]{P_{c 100}}}}
$$

where $\mathrm{Rg}$ is the global daily radiation (in $\mathrm{W}$ $\left.\mathrm{m}^{-2}\right) ; T$ is the mean daily air temperature $\left({ }^{\circ} \mathrm{C}\right) ; \lambda$ is the latent heat of evaporation $(\mathrm{J}$ $\left.\mathrm{g}^{-1}\right) ; P_{\mathrm{a}}$ is the daily rainfall $(\mathrm{mm}) ; P_{\mathrm{c} 100}$ is the rainfall of the last 4 days $(\mathrm{mm})$.

In eqn. 2, the numerator is a simple model of the evapotranspiration rate. It is built to roughly indicate the water status of the system and the moisture content of the fuel. DC values range from 0.1 (lowest danger conditions) to 5 (highest danger conditions). DC values lower than 0.1 are assumed $=0.1 ; D C$ values higher than 5 are assumed $=5$.

$M C$ accounts for the meteorological conditions favouring the maximum fire spread during the day and is derived modifying the results of previous works carried out in Sardinia (Palmieri et al. 1992 - eqn. 3):

$$
\begin{aligned}
M C=0.14 & {[\exp (0.0625 T x)} \\
& +\exp (0.1 W S) \\
& +\exp (-0.062 R H n)]
\end{aligned}
$$

where $T x$ is the maximum daily air temperature $\left({ }^{\circ} \mathrm{C}\right)$; WS is the maximum daily wind speed $\left(\mathrm{km} \mathrm{h}^{-1}\right) ; \mathrm{RHn}$ is the minimum daily air temperature.

MC ranges from 0.4 to 5 (minimum and maximum fire danger conditions respectively). $M C$ values lower than 0.4 are assumed $=0.4$; $M C$ values higher than 5 are assumed $=5$

$R$ is a coefficient accounting for the maximum daily solar radiation $R S x$ : if $R S x<400$ $\mathrm{W} \mathrm{m} \mathrm{m}^{-2}$ then $\mathrm{R}=0.24$; if $400 \mathrm{~W} \mathrm{~m}^{-2} \leq \mathrm{RSX} \leq$ $800 \mathrm{~W} \mathrm{~m}^{-2}$, then $\mathrm{R}=0.32$; if $R S x>800 \mathrm{~W}$ $\mathrm{m}^{-2}$, then $\mathrm{R}=1$.
$F C$ is related to the structural and physical characteristics of fuel and is computed as (eqn. 4):

$$
F C=L A I \cdot L A D \cdot D W
$$

where $L A l$ is the Leaf Area Index (dimensionless); $L A D$ is the Leaf Area Density $\left(=\mathrm{m}^{2}\right.$ of foliage $\mathrm{m}^{-3}$ ); DW is the fuel moisture content expressed as a fraction of the fresh fuel weight ( $0=100 \%$ of water; $1=0 \%$ of water).

The calculation of $F C$ required the definition of specific fuel categories (i.e., fuel models). A preliminary analysis of the available Sardinia soil cover maps allowed to identify and select 6 vegetation cover types representing about $50 \%$ of the total Sardinia surface: (1) broad leaf forest; (2) cork oak forest; (3) low shrubland; (4) tall shrubland; (5) garrigue; and (6) grassland. Data for FC calculation were derived from literature and field observations taken in different periods of the year in Sardinia.

The daily IFI value ranges from a minimum of 1.05 (lowest IFI value for grassland) to a maximum of 13.86 (highest IFI value for tall shrubland).

\section{Weather and fire dataset}

Fire and weather data are related to the years 2000-2007. We selected these years due to the high homogeneity of the available fire data and of the firefighting organisation, as both these factors could provide disturbances in the fire data series (Turco et al. 2016). Weather data were provided by ARPAS (Regional Environmental Protection Agency of Sardinia) from 48 weather stations. We calculated the daily FD values of each FD index per weather station. Then, following a previous climatic characterisation of Sardinia (Chessa et al. 1999), we identified 7 homogeneous climatic areas (CA) covering the whole island surface (Fig. 2) and assumed that the FD level in a given day could be considered uniform within each CA. The daily FD value per each FD index and CA area was calculated as the mean daily FD index value of the respective CA. The whole dataset is composed by 18,263 days, which is approximately $90 \%$ of the potential maximum number of days, as the entire year 2007 for the CA no. 2 and the whole period 2002-2006 for the CA no. 6 were discarded due to the high percentage of missing data. Fig. 3 shows an example of the daily trend of tested FD indexes in the CA no. 3, the number of fires, and the burned area recorded over the period 2000-2007.

\section{Spearman's rank correlation analysis}

To compare the different FD indexes, we normalized each daily FD index value per CA in a scale ranging from 0 to 100 as follows (eqn. 5):

$$
I_{n}=\frac{I-I_{\text {min }}}{I_{\text {max }}-I_{\text {min }}} \cdot 100
$$

where $I_{\mathrm{n}}$ is the normalised daily value, $I$ is

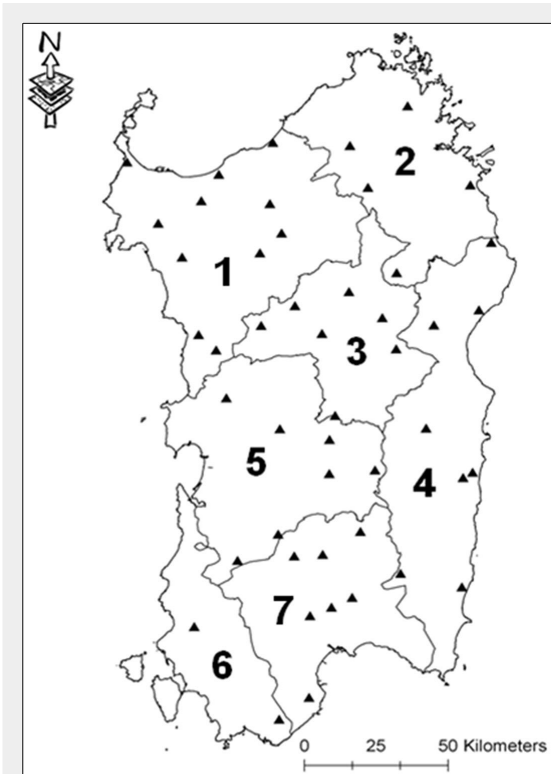

Fig. 2 - Climatic areas of Sardinia (here numbered from 1 to 7). Triangles indicate the location of the 48 weather stations used in this study.

the daily value, $I_{\min }$ and $I_{\max }$ are the absolute minimum and maximum daily values, respectively, calculated over the whole study period.

The normalised daily value $I_{\mathrm{n}}$ of each FD index per CA was expressed as FD danger class, considering $10 \mathrm{FD}$ classes of increasing FD degree (i.e., class 1: 0-9.99; class 2: 10-19.99; etc.). We then created a data matrix containing all the regional data, and the following fire parameters were calculated for each FD index and class (8 FD indexes $\times 10$ FD classes $=80$ rows):

- P1: the percentage of days with fires (days with fires with respect to all days per FD class). We used a threshold of 4 fires per day to exclude days with occasional or small fires);

- P2: the daily burned surface area per 50 $\mathrm{km}^{2}$;

- P3: the daily fire number per $50 \mathrm{~km}^{2}$;

- P4: the mean burned surface area per fire.

Based on the assumption that the value of the fire parameters should increase when the FD class increases, we applied the Spearman's rank correlation analysis to calculate the association between each FD index and the fire indicators, obtaining the correlation coefficient $\rho$ for the 8 FD indexes and the 4 fire parameters (10 pairs of data for each $\rho$ calculation). The highest $\rho$ value $(\rho=1)$ indicates a perfect match between the FD class and the value of a fire parameter (that is, the fire parameter value increases when the FD class in creases). Not all the selected parameters are totally independent and the relationships between FD indexes and fire activity are not always linear (Schoenberg et al. 2003). Nonetheless, the aim of the analysis was to investigate whether the increase in 


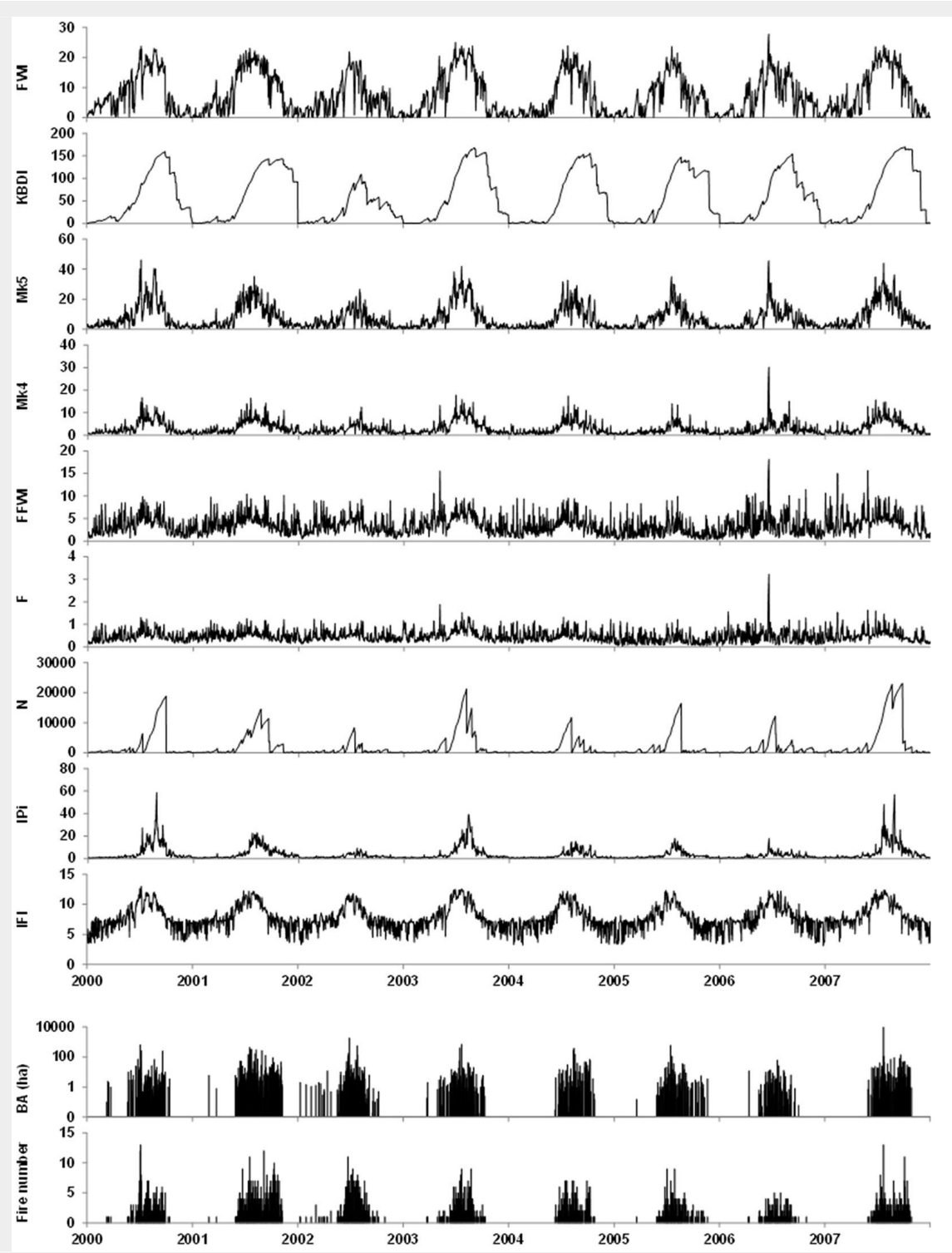

Fig. 3 - Mean daily values of the fire danger indexes within the climatic area $\mathrm{n}$. 3, along with observed fire number and burned area (BA) for the study period 2000-2007.

the observed fire activity was related to the increase in the fire danger class as indicated by each index. Assuming that higher $\rho$ values indicates a better index performance in predicting fire occurrence, a score related to the performance was calculated for each FD index by summing the $\rho$ coefficients $(p \leq 0.05)$. The higher is the score $(\min =0, \max =4)$, the higher is the index accuracy in predicting fire occurrence.

\section{Index value distribution and percentile analysis}

Percentile analysis of FD values distribution over a time interval provides useful information on its variability and can be used to determine if and how much the indicators of fire activities are correctly detected by the FD indexes.

We calculated per each $C A$ a further set of 5 fire metrics, which reflect low to severe observed occurrence of fire in terms of ignitions and burned surface area: (i) $A D$ (all days), days with and without fires (over 18,263 days); (ii) OFD (one fire days), days with at least one fire (6,140 days); (iii) MFD (more than one fire days), days with at least 1 fire per $1,000 \mathrm{~km}^{2}$ (2,758 days); (iv) LFD (large fire days in terms of total burned surface area): days with burned surface area larger than 0.5 ha per $50 \mathrm{~km}^{2}$ (719 days); (v) LAFD (large average fire days, in terms of mean burned surface area per fire), days with an average burned surface area per fire greater than 10 ha (495 days).

As an example of percentile analysis, the distribution values of 3 tested FD indexes for AD, OFD, MFD, LFD and LAFD related to 3 FD indexes are shown in Fig. 4. If no relationship exists between the index value and the fire activity indicators, all the distributions are expected to be similar to that of $A D$; vice versa, a distribution shifted to the right from $A D$ to LAFD (from the top to the bottom of Fig. 4, corresponding to an increase in fire activity) indicates that the index value is likely increasing when fire activity is progressively increasing. Fig. 5 reports the corresponding cumulative distribution curves for each FD index. For given percentile levels $\left(90^{\text {th }}, 75^{\text {th }}, 50^{\text {th }}\right.$, and $25^{\text {th }}$ thresholds were chosen in this study) we calculated for each FD index the difference between the indicators corresponding to different fire activity levels, in terms of the following 4 parameters (expressed in days): (i) all days minus fire days (AD-OFD); (ii) fire days minus multiple fire days (OFDMFD); (iii) multiple fire days minus large fire days (MFD-LFD); (iv) large fire days minus large average fire days (LFD-LAFD).

The higher the sum of these 4 values, the higher is the ability of the index to discriminate days with different fire activity levels. These sums were used to rank the FD indexes. The indexes with the lowest cumulative values are expected to be less accurate, overall, in discriminating days with different fire activity.

\section{Logistic regression}

The fire activity indicators OFD, MFD, LFD, LAFD can be considered as binary (true/false) response variables that can be predicted using sets of explanatory variables (e.g., values of a fire danger index or meteorological variables). The relationship between fire probability and the predictor variables can be described by a sigmoid function, which is almost linear only for intermediate values whereas tends asymptotically to 0 and 1 at the extremes. The use of logistic regression and logit-logarithmic transformation allows to express the response probability $(p)$ by a linear combination of a set of parameters (eqn. 6):

$$
\operatorname{logit}(p)=\log \left(\frac{p}{1-p}\right)=\alpha+\beta^{\prime} x
$$

where $\alpha$ is the intercept parameter, $\beta$ ' is the vector of the slope parameters, and $x$ is the explanatory variable value. The probability of occurrence of an event can be calculated as follows (eqn. 7):

$$
p_{\text {event }}=\frac{1}{1+e^{-\left(\alpha+\beta^{\prime} x\right)}}
$$

where $e$ is the base of natural logarithms. Such probability can be used for predicting fire activity indicators, which will take a value of 1 when the probability is higher than a suitable cut-off threshold, or zero otherwise.

Different methods exists to select the best-fitting logistic regression model, such as overall model accuracy, goodness-of-fit statistics, etc. (Menard 2002, Hosmer et al. 2013). We used the overall model accuracy to test for the prediction improvement determined by the inclusion of explanatory variables over the intercept-only model (the null model). The null hypothesis (i.e., all the explanatory effects in the model are equal to zero) was tested by the Wald's Chi-Square statistics $(\alpha=0.05)$. The Wald's statistic was also used to evaluate the significance of both the intercept and the pre- 
dictors included in the models. We also evaluated the goodness-of-fit of the logistic regression models using the HosmerLemeshow test (Hosmer et al. 2013). Moreover, for each model we calculated the Nagelkerke's $R^{2}$, which is an adjusted coefficient of determination which measures the increase in likelihood with respect to the null model when a predictor is included in the logistic model (Nagelkerke 1991).

An error matrix between observed and predicted values of the fire activity indicators was constructed and used to calculate the c-statistic (Hosmer et al. 2013), which may range from 0.5 (random association between observed and expected events) to 1.0 (full association). Models are typically considered predictives when the cstatistic value is higher than 0.7 , and strong to very accurate when exceeding 0.8-0.9. Moreover, the true/false positive values derived from the error matrix were used to assess the sensitivity (in terms of correctly classified fire events) and specificity (correctly classified non-fire events) of each model.

\section{Results}

Spearman's rank correlation analysis

The Spearman's correlation analysis was performed to obtain a general indication of the predicting performance of the FD indexes. IFI showed the highest score (4.00), indicating a perfect and positive correlation between the 4 fire parameters and the danger classes for the whole fire activity range (Tab. 2). Good results were also obtained by FFWI (score 3.55) and by the Canadian FWI (3.36). Mk5 and F indexes showed intermediate results, with a score value below 3. Fair to poor scores were observed for KBDI and IPi indexes. Mk4 and Nesterov indexes did not show any significant correlation.

\section{Index value distribution and percentile} analysis

Percentile analysis allowed to quantify the FD indexes response (in terms of its variability) at different fire activity levels. Fig. 5 shows an example of the observed percentile distribution of different fire ac-
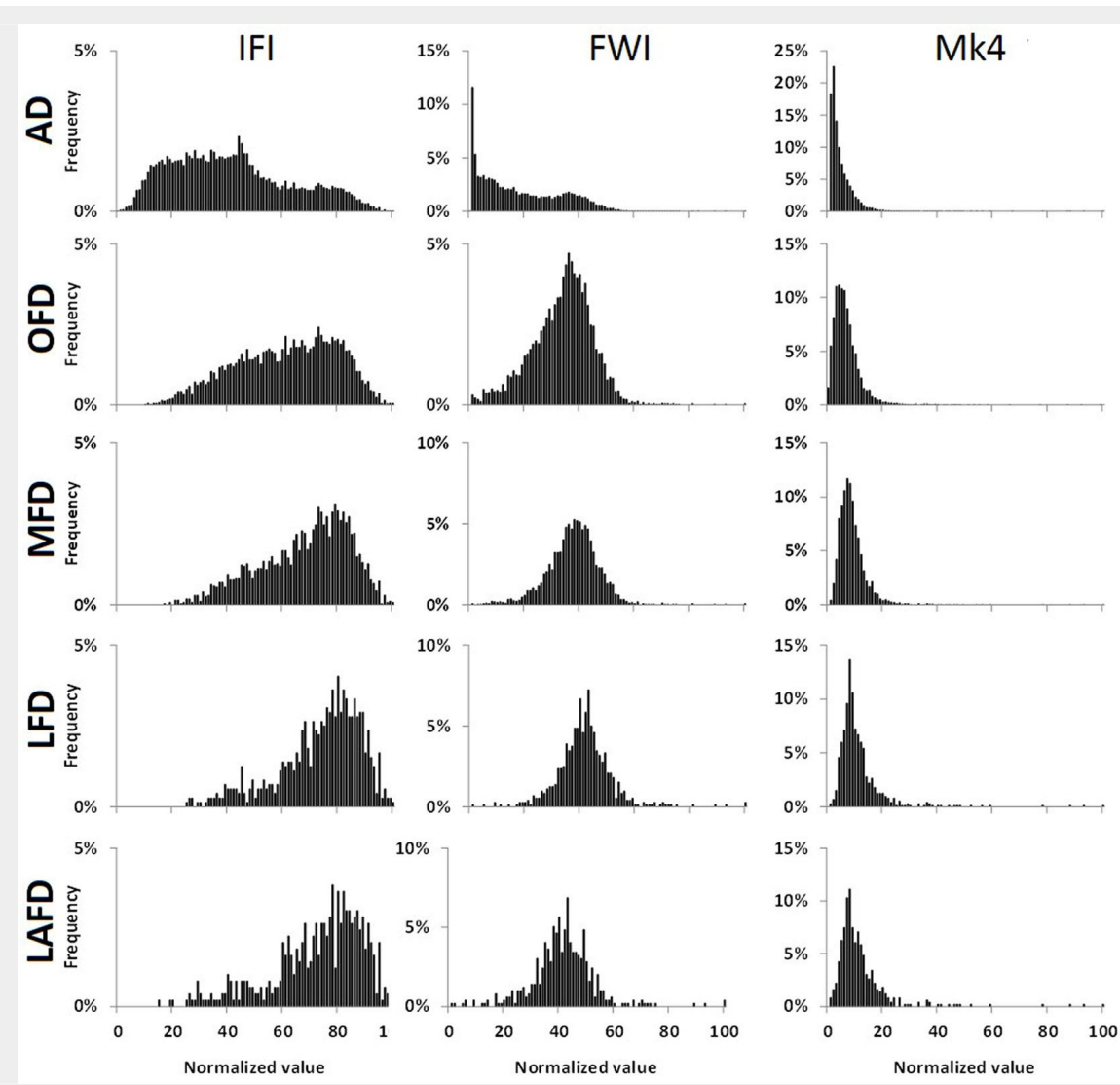

Fig. 4 - Frequency distribution of IFI, FWI, and Mk4 normalized values considering all days (AD), days with fires (OFD), multiple fire days (MFD), large fire days (LFD), and large average fire days (LAFD).

tivity parameters for IFI, FWI, and Mk4 indexes. The differences between the values of each index at selected percentile levels are reported in Tab. 3. The sum of these differences can be used to quantify the shift of each distribution under different fire activity conditions. Overall, the ranking based on the sum-of-differences revealed a good performance of the IFI and Mk5 indexes. IFI provided accurate estimates of days with low to high fire occurrence activity, except for very high fire occurrence. Mk5 well estimated medium to very high fire occurrence. KBDI was the third index in the overall ranking, and had the first and the second rank at low (OFD-AD) and high
(LAFD-LFD) fire activity conditions, respectively. KBDI showed to well predict days with fire ignitions and days with very high fire occurrence, but it appears to be a poor indicator of potential severity for intermediate fire activity conditions. FWI was the fourth index in the overall ranking.

\section{Logistic regression}

The set of logistic regression models and the related statistics calculated using the different combination of predictive and dependent variables (fire activity indicators) is showed in Tab. 4. All the logistic regression models were significant $(p<0.001)$ after Wald's test, indicating that all models

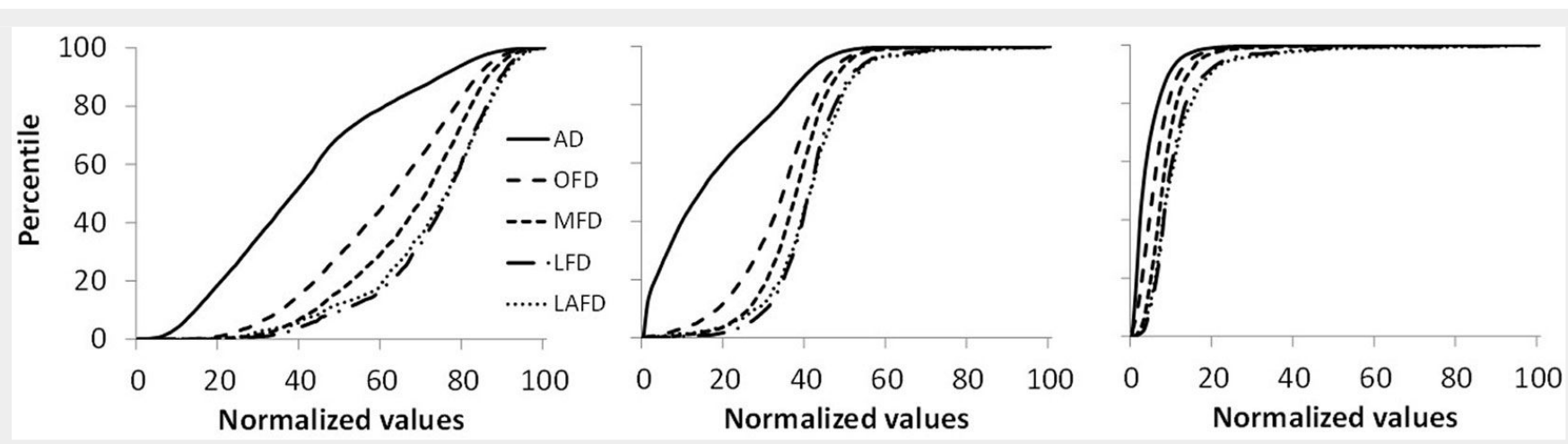

Fig. 5 - Percentile distribution of different fire activity parameters obtained using the FD indexes IFI (left), FWI (center), and Mk4 (right). (AD): all days; (OFD): days with fires; (MFD): multiple fire days; (LFD): large fire days; (LAFD): large average fire days. 
Tab. 2 - Spearman's coefficients $(\rho)$ calculated for the fire danger indexes used in the analysis. (P1): \% of days with at least 4 fires over all days of that class; ( $\mathrm{P} 2)$ : burned area (in ha) over 50 $\mathrm{km}^{2}$; (P3): daily fire number over $50 \mathrm{~km}^{2}$; (P4): mean burned area (in ha) per fire. The score is obtained as the sum of the $\rho$ of each index (only $\rho$ with $p \leq 0.05$ were considered). (**): $p \leq$ $0.01 ;(*)$ : $\leq$ 0.05; (ns): not significant.

\begin{tabular}{lccccc}
\hline FD Index & P1 & P2 & P3 & P4 & Score \\
\hline FWI & $0.83^{* *}$ & $0.85^{* *}$ & $0.85^{* *}$ & $0.82^{* *}$ & 3.36 \\
KBDI & $0.87^{* *}$ & $0.50^{\text {ns }}$ & $0.90^{* *}$ & $0.37^{\text {ns }}$ & 1.77 \\
Mk5 & $0.31^{\text {ns }}$ & $0.87^{* *}$ & $0.87^{* *}$ & $0.87^{* *}$ & 2.60 \\
Mk4 & $0.56^{\text {ns }}$ & $0.58^{\text {ns }}$ & $0.32^{\text {ns }}$ & $0.39^{\text {ns }}$ & - \\
FFWI & $0.84^{* *}$ & $0.95^{* *}$ & $0.88^{* *}$ & $0.88^{* *}$ & 3.55 \\
F & $0.93^{* *}$ & $0.73^{*}$ & $0.94^{* *}$ & $0.56^{\text {ns }}$ & 2.60 \\
N & $0.10^{\text {ns }}$ & $-0.25^{\text {ns }}$ & $-0.14^{\text {ns }}$ & $-0.49^{\text {ns }}$ & - \\
IPi & $0.77^{*}$ & $0.52^{\text {ns }}$ & $0.76^{*}$ & $0.33^{\text {ns }}$ & 1.52 \\
IFI & $1.00^{* *}$ & $1.00^{* *}$ & $1.00^{* *}$ & $1.00^{* *}$ & 4.00 \\
\hline
\end{tabular}

Tab. 3 - Sum of the differences of the fire danger index value for the $25^{\text {th }}, 50^{\text {th }}, 75^{\text {th }}$ and $90^{\text {th }}$ percentile between different fire activity conditions, and ranking.

\begin{tabular}{|c|c|c|c|c|c|c|c|c|c|c|}
\hline \multirow[b]{2}{*}{ 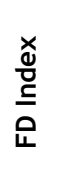 } & \multicolumn{5}{|c|}{$\Sigma$ of differences } & \multicolumn{5}{|c|}{ Ranking } \\
\hline & 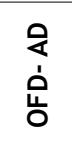 & $\begin{array}{l}\text { 는 } \\
\text { ò } \\
\text { 닟 }\end{array}$ & 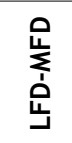 & 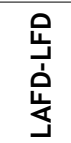 & Sum & 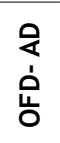 & $\begin{array}{l}00 \\
\text { 이 } \\
\text { 눈 } \\
\text { L }\end{array}$ & 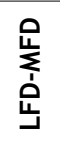 & 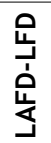 & Rank \\
\hline FWI & 58.3 & 13.0 & 14.7 & 1.7 & 87.8 & 4 & 4 & 4 & 3 & 4 \\
\hline KBDI & 87.9 & 6.8 & -1.6 & 2.6 & 95.7 & 1 & 7 & 9 & 2 & 3 \\
\hline Mk5 & 55.1 & 18.9 & 26.5 & 2.9 & 103.4 & 5 & 3 & 1 & 1 & 2 \\
\hline Mk4 & 13.1 & 5.1 & 9.3 & 1.3 & 28.7 & 8 & 9 & 7 & 4 & 9 \\
\hline FFWI & 14.2 & 6.2 & 12.6 & 0.0 & 33.1 & 7 & 8 & 5 & 5 & 8 \\
\hline $\mathrm{F}$ & 11.5 & 7.1 & 17.7 & -0.1 & 36.2 & 9 & 6 & 3 & 6 & 7 \\
\hline$N$ & 63.6 & 19.1 & 7.4 & -4.4 & 85.8 & 3 & 2 & 8 & 9 & 5 \\
\hline $\mathrm{IPi}$ & 23.8 & 11.2 & 9.6 & -0.6 & 44.0 & 6 & 5 & 6 & 7 & 6 \\
\hline IFI & 77.8 & 24.6 & 23.4 & -2.9 & 122.9 & 2 & 1 & 2 & 8 & 1 \\
\hline
\end{tabular}

Tab. 4 - Logistic regression model statistics obtained for the dependent variables fire days (OFD), multiple fire days (MFD), large fire days (LFD), and large area fire days (LAFD) using the values of the fire danger indexes tested in this study as predictors. (A): All regression models showed significant $(p<0.001)$ values of the Wald's statistics for both the constant term and the predictor variables; (B): values of the chi-square statistics marked with an asterisk $\left(^{*}\right)$ are significant after the Hosmer-Lemeshow test ( $p>0.01$ ), thus rejecting the null hypothesis of lack of fit.

\begin{tabular}{|c|c|c|c|c|c|c|}
\hline $\begin{array}{l}\text { Output } \\
\text { Variable }\end{array}$ & $\begin{array}{l}\text { FD Index } \\
\text { (predictor) }\end{array}$ & $\begin{array}{l}\text { Constant }{ }^{(A)} \\
(B \pm S E)\end{array}$ & $\begin{array}{l}\text { Predictor }^{(A)} \\
\quad(B \pm S E)\end{array}$ & $\begin{array}{l}\text { Nagelkerke } \\
R^{2}\end{array}$ & $\begin{array}{l}\text { Hosmer-Lemeshow } \\
\chi^{2}\end{array}$ & c-statistic \\
\hline \multirow[t]{9}{*}{ OFD } & IFI & $-5.309 \pm 0.083$ & $0.101 \pm 0.002$ & 0.57 & 90.6 & 0.89 \\
\hline & FWI & $-4.136 \pm 0.065$ & $0.165 \pm 0.006$ & 0.66 & 69.77 & 0.93 \\
\hline & Mk5 & $-3.323 \pm 0.05$ & $0.189 \pm 0.003$ & 0.60 & 531.9 & 0.92 \\
\hline & Mk4 & $-2.698 \pm 0.042$ & $0.490 \pm 0.009$ & 0.45 & 561.04 & 0.88 \\
\hline & $\mathrm{F}$ & $-1.529 \pm 0.038$ & $0.057 \pm 0.002$ & 0.07 & 259.96 & 0.66 \\
\hline & FFWI & $-1.772 \pm 0.039$ & $0.078 \pm 0.002$ & 0.12 & 518.6 & 0.71 \\
\hline & KBDI & $-2.361 \pm 0.039$ & $0.045 \pm 0.001$ & 0.37 & 742.71 & 0.84 \\
\hline & $\mathrm{IPi}$ & $-2.451 \pm 0.038$ & $0.401 \pm 0.008$ & 0.48 & 1171.5 & 0.90 \\
\hline & $N$ & $-1.740 \pm 0.028$ & $0.144 \pm 0.003$ & 0.46 & 1775.8 & 0.90 \\
\hline \multirow[t]{9}{*}{ MFD } & $\mathrm{IFI}$ & $-6.194 \pm 0.107$ & $0.084 \pm 0.002$ & 0.45 & 53.93 & 0.89 \\
\hline & FWI & $-5.129 \pm 0.092$ & $0.129 \pm 0.006$ & 0.48 & 116.36 & 0.91 \\
\hline & Mk5 & $-3.728 \pm 0.056$ & $0.106 \pm 0.002$ & 0.40 & 459.97 & 0.90 \\
\hline & Mk4 & $-3.134 \pm 0.047$ & $0.274 \pm 0.007$ & 0.27 & 644.83 & 0.87 \\
\hline & $\mathrm{F}$ & $-2.634 \pm 0.048$ & $0.058 \pm 0.002$ & 0.07 & 243.11 & 0.69 \\
\hline & FFWI & $-2.743 \pm 0.048$ & $0.068 \pm 0.003$ & 0.09 & 435.34 & 0.73 \\
\hline & KBDI & $-3.279 \pm 0.055$ & $0.037 \pm 0.001$ & 0.22 & 619.06 & 0.79 \\
\hline & $\mathrm{IPi}$ & $-2.716 \pm 0.038$ & $0.153 \pm 0.004$ & 0.26 & 1029.4 & 0.88 \\
\hline & $N$ & $-2.482 \pm 0.034$ & $0.057 \pm 0.001$ & 0.25 & 1228.9 & 0.87 \\
\hline \multirow[t]{9}{*}{ LFD } & $\mathrm{IFI}$ & $-8.308 \pm 0.228$ & $0.086 \pm 0.003$ & 0.33 & 6.79 * & 0.90 \\
\hline & FWI & $-6.885 \pm 0.181$ & $0.123 \pm 0.01$ & 0.33 & 15.12 * & 0.91 \\
\hline & Mk5 & $-5.109 \pm 0.097$ & $0.084 \pm 0.003$ & 0.29 & 103.78 & 0.90 \\
\hline & Mk4 & $-4.402 \pm 0.076$ & $0.200 \pm 0.008$ & 0.19 & 207.68 & 0.88 \\
\hline & $\mathrm{F}$ & $-4.416 \pm 0.086$ & $0.071 \pm 0.004$ & 0.09 & 96.23 & 0.75 \\
\hline & FFWI & $-4.385 \pm 0.084$ & $0.073 \pm 0.004$ & 0.09 & 140.8 & 0.77 \\
\hline & KBDI & $-4.501 \pm 0.1$ & $0.030 \pm 0.002$ & 0.10 & 232.45 & 0.75 \\
\hline & $\mathrm{IPi}$ & $-3.788 \pm 0.058$ & $0.078 \pm 0.004$ & 0.12 & 458.24 & 0.85 \\
\hline & $N$ & $-3.802 \pm 0.06$ & $0.039 \pm 0.002$ & 0.12 & 390.56 & 0.85 \\
\hline \multirow[t]{9}{*}{ LAFD } & $\mathrm{IFI}$ & $-8.229 \pm 0.255$ & $0.078 \pm 0.003$ & 0.27 & 12.62 * & 0.88 \\
\hline & FWI & $-6.965 \pm 0.199$ & $0.113 \pm 0.011$ & 0.28 & $4.13^{*}$ & 0.89 \\
\hline & Mk5 & $-5.465 \pm 0.114$ & $0.080 \pm 0.003$ & 0.25 & 57.32 & 0.88 \\
\hline & Mk4 & $-4.700 \pm 0.087$ & $0.178 \pm 0.008$ & 0.17 & 99.02 & 0.86 \\
\hline & $\mathrm{F}$ & $-4.844 \pm 0.102$ & $0.070 \pm 0.004$ & 0.09 & 31.29 & 0.74 \\
\hline & FFWI & $-4.772 \pm 0.099$ & $0.070 \pm 0.004$ & 0.08 & 53.25 & 0.75 \\
\hline & KBDI & $-4.970 \pm 0.124$ & $0.031 \pm 0.002$ & 0.09 & 130.33 & 0.76 \\
\hline & $\mathrm{IPi}$ & $-4.186 \pm 0.069$ & $0.073 \pm 0.004$ & 0.11 & 208.24 & 0.85 \\
\hline & $\mathrm{N}$ & $-4.193 \pm 0.073$ & $0.037 \pm 0.002$ & 0.10 & 265.18 & 0.83 \\
\hline
\end{tabular}



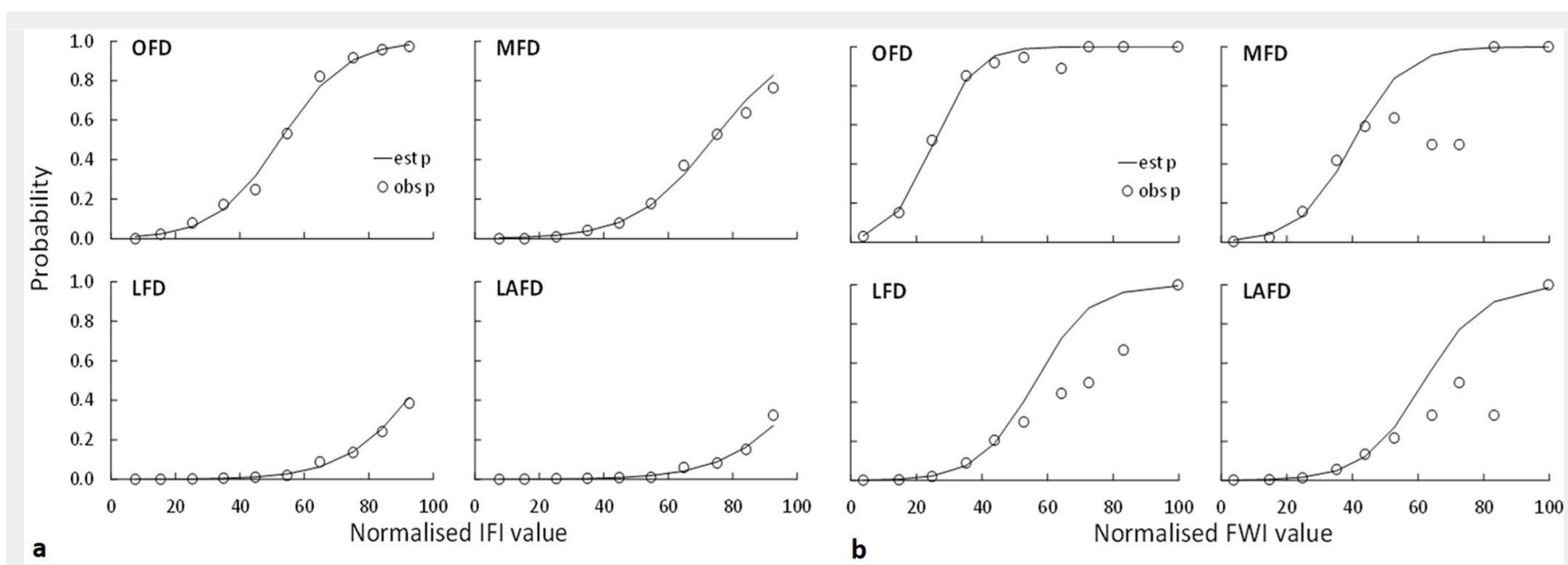

Fig. 6 - Estimated (solid line) vs. observed (points) probabilities obtained by the logistic model developed using IFI (a) and FWI (b) indexes as predictor variable of the fire activity indicators. (OFD): days with fires; (MFD): multiple fire days; (LFD): large fire days; (LAFD): large average fire days.

were more accurate than the null model, and that all predictors were significantly related with the outcome variables (OFD, MFD, LFD, LAFD). The usefulness of the explanatory variables in predicting the response variable was also evaluated by the Nagelkerke's $R^{2}$, which reflects the amount of variation in fire activity indexes accounted for by the models. The models developed using FWI, IFI and Mk5 as predictors had the highest values of the Nagelkerke's $R^{2}$, in particular when FD $\left(R^{2}=0.6\right.$ $0.7)$ and MFD $\left(R^{2}=0.4-0.5\right)$ were included (Tab. 4). Lower values were obtained for the fire activity indicators LAFD and LFD, though IFI, FWI and $\mathrm{Mk}_{5}$ indexes still yielded the best results.

The accuracy of the models in predicting the observed values of fire activity indicators is reported in Tab. 4. The HolmerLemeshow test revealed no significant differences between observed and expected probabilities only using IFI and FWI as predictors and LAFD and LFD as independent variables. All the other models did not adequately fit the outcome variables after the Hosmer-Lemeshow's test (Tab. 4).

Most of the models showed values of the c-statistic above the threshold of 0.9 , indicating a high accuracy in assigning the higher probabilities to the fire activity indicator events (Tab. 4). However, the higher values of c-statistic were observed for all the fire activity indicators using the indexes $\mathrm{IFI}, \mathrm{FWI}, \mathrm{Mk}_{5}, \mathrm{Mk}_{4}, \mathrm{IPi}$, and $\mathrm{N}$ as predictors. The IFI index showed the best accuracy for all fire activity indicators and over the entire index range (Fig. 6). FWI showed a good accuracy for OFD, but a strong overestimation of the observed probability for MFD, LFD, and LAFD at index values greater than 45 (Fig. 6).

Model comparison showed that the best fitting models were those including IFI and FWI as predictors of LAFD and LFD. Regarding OFD and MFD, the different explanatory variables provided closest results, and even the models $\mathrm{Mk}_{5}, \mathrm{IPi}$, and $\mathrm{F}$ showed a significant fit to observations.

\section{Discussion and conclusions}

In this study we applied a statistical approach to assess the ability of fire danger indexes to predict fire occurrence. This issue is still quite debated and the scientific fire community is far from a shared and standardized solution to this problem.

Eight fire danger indexes were arbitrarily chosen and $a$ posteriori evaluated for their ability to represent the observed fire activity on daily basis in a typical Mediterranean area. Seven of these indexes are typically weather-based indexes, thus requiring only weather observations as input data. Contrastingly, the IFI index requires also fuel structure and fuel moisture information. In the analysis we assumed that the performance of a fire danger index is good when the fire danger index value (or the related fire danger class) increases when the observed fire activity (expressed as fire activity indicators) increases.

Although not all the statistical tests indicated the same FD index ranking, several indexes clearly exhibited better performances. The overall results indicate that IFI and FWI well estimate the observed fire occurrence. As mentioned above, the majority of the FD indexes are weather-based (do not account for ignitions); nevertheless, the correlation analysis confirmed the good performance of all indexes to represent ignitions ( $\mathrm{P} 1$ indicator), despite a large part of fires in Sardinia are human-caused and about half of fire ignitions are classified as arson (Salis et al. 2013, Sardinia Forest Service, personal communication). Hence, it could be hypothesized that a correlation exists between arsonists activity and FD conditions in the study area.

The high predictive potential of FWI was confirmed in a recent work which analysed wildland fire data from Sardinia (Italy) and Corsica (France) using non-parametric statistical models to understand the interactive effects of anthropogenic and weather variables on spatio-temporal patterns of fire occurrence and size in relation to weather, land use, anthropogenic features, and time of the year. They found that the FWI has a relevant predictive value in discriminating the days with high fire potential. Also, Urbieta et al. (2015) highlighted that FWI had good ability in predicting fire activity in a study carried out in 5 southern countries of the European Union and the Pacific Western coast of the USA.

In this study, the IFI index showed the best performance over all the analyses carried out, showing a good association between observed and predicted probabilities for all the fire activity indicators over the entire FD range. The results of the logistic regression models suggested that IFI and FWI had similar performance in estimating the fire activity indicators, both at low (OFD, MFD) and high (LFD, LAFD) fire activity conditions. The Nagelkerke $R^{2}$ values observed, ranging from 0.4 to 0.7 for both IFI and FWI, are slightly higher than those (0.00-0.54) obtained by Martell et al. (1987) and similar to those (0.25-0.77) reported by Padilla \& Vega-García (2011). The chi-square values provided by the HosmerLemeshow test for both IFI and FWI, are similar to the values reported by Vicente López \& Crespo Abril (2012) during the validation of a wildland fire danger (WFD) index developed in the community of Valencia (Spain). In Mediterranean areas FWI was successfully tested, although some authors (Dimitrakopoulos et al. 2011) argued that the absence or the rare presence of deep fuel layers (related to the DC and DMC submodules of the FWI) can partially reduce the performance of the FWI in these areas.

From an operational point of view, our results revealed that IFI and FWI yielded better predictions than the other indexes. IFI had slightly better results than FWI, but its application outside the case study area requires a careful evaluation of input data, in particular for the Fuel Code parametriza- 
tion. On the other hand, our results confirmed previous studies indicating that the widely used FWI index is suitable for an operational use in Sardinia, a typical fireprone Mediterranean region. Therefore, a combined use of both IFI and FWI in a short-term fire danger forecast chain would be complementary and useful for FD analysis and the evaluation by fire managers.

\section{Acknowledgements}

This work was partially funded by: (i) the Italian Ministry of Education University and Research (MIUR), National Research Project PRIN: "Climate change mitigation strategies in tree crops and forestry in Italy (CARBOTREES)" (prot. 201049EXTW); (ii) the Italian Ministry of Education University and Research (MIUR), "Gemina" Project (grant agreement 232/2011); (iii) the Regional Government of Sardinia, LR7/2007, project "EXTREME - Messa a punto di metodologie e sistemi di supporto per la valutazione del rischio di incendio in condizioni meteorologiche estreme" (CRP-25405).

\section{References}

Andrews PL, Bradshaw LS (1997). Fires: fire information retrieval and evaluation system - a program for fire danger rating analysis. General Technical Report INT-GTR-367, Intermountain Research Station, USDA Forest Service, Ogden, UT, USA, pp. 64. - doi: 10.2737/INT-GTR-367 Andrews PL, Loftsgaarden DO, Bradshaw LS (2003). Evaluation of fire danger rating indexes using logistic regression and percentile analysis. International Journal of Wildland Fire 12: 213-226. - doi: 10.1071/WF02059

Arndt N, Vacik H, Koch V, Arpaci A, Gossow H (2013). Modeling human-caused forest fire ignition for assessing forest fire danger in Austria. iForest 6 (5): 315-325. - doi: 10.3832/iforo936006

Cardil A, Molina DM, Kobziar LN (2014). Extreme temperature days and their potential impacts on southern Europe. Natural Hazards and Earth System Sciences 14 (11): 3005-3014. - doi: 10.519 4/nhess-14-3005-2014

Chessa PA, Cesari D, Delitala AM (1999). Mesoscale regimes of precipitation and temperature over Sardinia (Italy) and their related synoptic circulations. Theoretical and Applied Climatology 63: 195-222. - doi: 10.1007/s0070400 50103

Cruz MG, Viegas DX (1998). Fire behaviour in some common central Portugal fuel complexes: evaluation of fire behavior models performances. In: Proceedings of the "III International Conference on Forest Fire Research and the $14^{\text {th }}$ Conference on Fire and Forest Meteorology" (DX Viegas ed). Luso (Coimbra, Portugal), $16-20$ Nov 1998. ADAl, Coimbra, Portugal, pp. 829-875.

Curt T, Borgniet L, Bouillon C (2013). Wildfire frequency varies with the size and shape of fuel types in southeastern France: implications for environmental management. Journal of Environmental Management 117: 150-161. - doi: 10.1016/j.jenvman.2012.12.006

Curt T, Fréjaville T, Lahaye S (2016). Modelling the spatial patterns of ignition causes and fire regime features in southern France: implications for fire prevention policy. International Journal of Wildland Fire 25 (7): 785-796. - doi: 10.1071/WF15205

Dimitrakopoulos AP, Bemmerzouk AM, Mitsopoulos ID (2011). Evaluation of the Canadian fire weather index system in an eastern Mediterranean environment. Meteorological Applications 18 (1): 83-93. - doi: 10.1002/met.214

Fernandes PM, Loureiro C, Guiomar N, Pezzatti GB, Manso FT, Lopes L (2014). The dynamics and drivers of fuel and fire in the Portuguese public forest. Journal of Environmental Management 146: 373-382. - doi: 10.1016/j.jenvman. 2014.07.049

Giannakopoulos C, LeSager P, Moriondo M, Bindi M, Karali A, Hatzaki M, Kostopoulou E (2012). Comparison of fire danger indexes in the Mediterranean for present day conditions. iForest 5: 197-203. - doi: 10.3832/iforo622-005

Haines DA, Main WA, Frost JS, Simard AJ (1983). Fire-danger rating and wildfire occurrence in the northeastern United States. Forest Science 66: 159-164. [online] URL: http://academic.oup. com/forestscience/article-abstract/29/4/679/46 56770

Heinsch A, Andrews PL, Kurth LL (2009). Implications of using percentiles to define fire danger levels. In: Proceedings of the " $8^{\text {th }}$ Symposium on Fire and Forest Meteorology". American Meteorological Society (Boston, MA, USA) 12-15 Oct 2009, extended abstract P1.5. [online] URL: http://ams.confex.com/ams/pdfpapers/156081. pdf

Hosmer DW, Lemeshow S, Sturdivant RX (2013). Applied logistic regression ( $3^{\text {rd }}$ edn). John Wiley and Sons, Inc., Hoboken, NJ, USA, pp. 528.

Keetch JJ, Byram G (1968). A drought index for forest fire control. Research Paper SE-38, Southeastern Forest Experiment Station, USDA Forest Service, Asheville, NC, USA, pp. 32.

Krusel N, Packham D, Tapper N (1993). Wildfire activity in the mallee shrubland of Victoria, Australia. International Journal of Wildland Fire 3 (4): 217-227. - doi: 10.1071/WF9930217

Levin N, Tessler N, Smith A, Mcalpine C (2016). The human and physical determinants of wildfires and burnt areas in Israel. Environmental management 58: 549-562. - doi: 10.1007/s00267016-0715-1

Lovreglio R, Leone V, Giaquinto P, Notarnicola A (2010). Wildfire cause analysis: four case-studies in southern Italy. iForest 3: 8-15. - doi: 10.38 32/ifor0521-003

Mandallaz D, Ye R (1997). Prediction of forest fires with Poisson models. Canadian Journal of Forest Research 27: 1685-1694. - doi: 10.1139/ x97-103

Martell DL, Otakel S, Stocks BJ (1987). A logistic model for predicting daily people caused fire occurrence in Ontario. Canadian Journal of Forest Research 17: 394-401. - doi: 10.1139/x87-068 Meddour-Sahar O, Meddour R, Leone V, Lovreglio R, Derridj A (2013). Analysis of forest fires causes and their motivations in North Algeria: the Delphi method. iForest 6: 247-254. doi: 10.3832/iforoog8-006

Menard S (2002). Applied logistic regression analysis. Series "Quantitative Applications in Social Sciences", Sage University Paper Series, vol. 07-106, Thousand Oaks, CA, USA, pp. 111. [online] URL: http://books.google.com/books? id=EAl1QmUUsbUC

Nagelkerke NJD (1991). A note on a general definition of the coefficient of determination. Biometrika 78: 691-692. - doi: 10.1093/biomet/ 78.3.691

Nesterov VG (1949). Combustibility of the forest and methods for its determination. USSR State Industry Press, Golesbumaga, Moscow, Russia, pp. 76. [in Russian]

Noble IR, Bary GAV, Gill AM (1980). McArthur's fire-danger meters expressed as equations. Australian Journal of Ecology 5: 201-203. - doi: 10.1111/j.1442-9993.1980.tbo1243.x

Oliveira S, Oehler F, San-Miguel-Ayanz J, Camia A, Pereira JMC (2012). Modeling spatial patterns of fire occurrence in Mediterranean Europe using multiple regression and random forest. Forest Ecology and Management 275: 117129. - doi: 10.1016/j.foreco.2012.03.003

Oliveira S, Zêzere JL, Queirós $M$, Pereira JM (2017). Assessing the social context of wildfireaffected areas. The case of mainland Portugal. Applied Geography 88: 104-117. - doi: 10.1016/j. apgeog.2017.09.004

Padilla M, Vega-García C (2011). On the comparative importance of fire danger rating indexes and their integration with spatial and temporal variables for predicting daily human-caused fire occurrences in Spain. International Journal of Wildland Fire 20: 46-58. - doi: 10.1071/WFo9139 Palmieri S, Inghilesi R, Siani AM, Martellacci C (1992). Un indice meteorologico di rischio per incendi boschivi [A meteorological index for the wildfire risk]. Bollettino Geofisico 15: 49-62. [in Italian]

Pausas JG, Fernández-Muñoz S (2012). Fire regime changes in the Western Mediterranean Basin: from fuel-limited to drought-driven fire regime. Climatic Change 110: 215-226. - doi: 10.10 07/s10584-011-0060-6

Ruffault J, Moron V, Trigo RM, Curt T (2017). Daily synoptic conditions associated with large fire occurrence in Mediterranean France: evidence for a wind-driven fire regime. International Journal of Climatology 37 (1): 524-533. doi: $10.1002 / j o c .4680$

Ruiz-Mirazo J, Martinez Fernandez J, Vega-Carcia C (2012). Pastoral wildfires in the Mediterranean: understanding their linkages to land cover patterns in managed landscapes. Journal of Environmental Management 98: 43-50. - doi: 10.1016/j.jenvman.2011.12.017

Russo A, Gouveia CM, Páscoa P, Dacamara CC, Sousa PM, Trigo RM (2017). Assessing the role of drought events on wildfires in the Iberian peninsula. Agriculture and Forest Meteorology 237: 50-59. - doi: 10.1016/j.agrformet.2017.01.021 Salis M, Ager AA, Arca B, Finney MA, Bacciu V, Duce $P$, Spano D (2013). Assessing exposure of human and ecological values to wildfire in Sardinia, Italy. International Journal of Wildland Fire 22: 549-565. - doi: 10.1071/WF11060 Salis M, Del Giudice L, Arca B, Ager AA, AlcasenaUrdiroz F, Lozano O, Bacciu V, Spano D, Duce P (2018). Modeling the effects of different fuel treatment mosaics on wildfire spread and behavior in a Mediterranean agro-pastoral area. Journal of Environmental Management 212: 490-505. - doi: 10.1016/j.jenvman.2018.02.020 
Salis M, Laconi M, Ager AA, Alcasena FJ, Arca B, Lozano OM, Oliveira AS, Spano D (2016). Evaluating alternative fuel treatment strategies to reduce wildfire losses in a Mediterranean area. Forest Ecology and Management 368: 207-221. doi: 10.1016/j.foreco.2016.03.009

San-Miguel-Ayanz J, Durrant T, Boca R, Libertà G, Boccacci F, Di Leo M, López Pérez J, Schulte E (2015). Forest Fires in Europe, Middle East and North Africa 2015. Publications Office of the European Union, EUR 28148 EN, Luxembourg, pp. 122.

San-Miguel-Ayanz J, Schulte E, Schmuck G, Camia A, Strobl P, Liberta G, Giovando C, Boca R, Sedano F, Kempeneers P, Mclnerney D, Withmore C, Santos De Oliveira S, Rodrigues M, Durrant T, Corti P, Oehler F, Vilar L, Amatulli G (2012). Comprehensive monitoring of wildfires in Europe: the European Forest Fire Information System (EFFIS). In: "Approaches to Managing Disaster - Assessing Hazards, Emergencies and Disaster Impacts" (Tiefenbacher J ed). InTech, Rijeka, Croatia, pp. 87-108. - doi: 10.5772/28441

Schoenberg FP, Peng R, Huang Z, Rundel P
(2003). Detection of non-linearities in the dependence of burn area on fuel age and climatic variables. International Journal of Wildland Fire 12: 1-6. - doi: 10.1071/WF02053

Sharples JJ, McRae RHD, Weber RO, Gill AM (2009). A simple index for assessing fire danger rating. Environmental Modelling and Software 24: 764-774. - doi: 10.1016/j.envsoft.2008.11.004 Sirca C, Spano D, Duce P, Delogu G, Cicalò GO (2007). Performance of a newly developed integrated fire rating index in Sardinia, Italy. In Proceedings of "Wildfire $2007-4^{\text {th }}$ International Wildland Fire Conference" (Viegas XD ed). Seville (Spain) 13-17 May 2007. Ministry of Environment, Madrid, Spain and Junta de Andalucia, Seville, Spain. [CD-ROM]

Turco M, Bedia J, Di Liberto F, Fiorucci P, Von Hardenberg J, Koutsias N, Llasat MC, Xystrakis F, Provenzale A (2016). Decreasing Fires in Mediterranean Europe. PLOS ONE 11 (3): e0150663. - doi: 10.1371/journal.pone. 0150663

Urbieta IR, Zavala G, Bedia J, Gutiérrez JM, San Miguel-Ayanz J, Camia A, Keeley JE, Moreno JM (2015). Fire activity as a function of fire-weather seasonal severity and antecedent climate across spatial scales in southern Europe and Pacific western USA. Environmental Research Letters 10: 11. - doi: http://iopscience.iop.org/ar ticle/10.1088/1748-9326/10/11/114013/meta

Van Wagner CE (1987). Development and structure of the Canadian Forest Fire Weather Index System. Forestry Technical Report no. 35, Canadian Forestry Service, Ottawa, ON, Canada, pp. 37.

Ventura F, Marletto V, Zinoni F (2001). Un metodo per il calcolo dell'indice meteorologico del rischio di incendio forestale [A method for the meteorological wildfire risk calculation]. Sherwood 68: 13-16. [in Italian]

Vicente López FJD, Crespo Abril F (2012). A new wildland fire danger index for a Mediterranean region and some validation aspects. International Journal of Wildland Fire 21 (8): 1030-1041. - doi: 10.1071/WF11046

Viegas XD (1999). Comparative study of various methods of fire danger evaluation in southern Europe. International Journal of Wildland Fire 9 (4): 235-246. - doi: 10.1071/WFooo15 